\title{
Do Epidemiological Parameters in Patients with Localized Prostate Cancer have an Influence on whether a Patient is Envisaged for Surgery or Brachytherapy?
}

\author{
Ruth Kirschner-Hermanns*, Thomas Klementz, Gerhard Jakse and Bernhard Brehmer
}

\author{
Urological Clinic, University Clinic Aachen, Germany
}

\begin{abstract}
Introduction: Only few studies comparing treatment outcome for patients with localized prostate cancer control their results for the possible confounding of demographic and clinical parameters. This fact prompted us to compare epidemiological data of patients before receiving brachytherapy (BT) to patients envisaged for radical prostatectomy (RP).
\end{abstract}

Methodology: We looked at demographic and clinical data as well as standardized questionnaires for 856 patients. In a logistic regression analysis parameters proven to be significantly different in a university analysis were further analyzed.

Results: Data of 676 patients (79\%) could be evaluated. Patients before radical prostatectomy (RPP) scored best in physical functioning, role functioning and sexual activity. Patients planned for low-dose rate brachytherapy (LDR) indicated the biggest problems in partnership and sexuality. The health insurance status was not equally distributed. However, in a logistic regression analysis of patients envisaged for surgical treatment only age and physical functioning could be identified as independent factors that differ significantly between treatment groups $(\mathrm{p}<0.01)$, but not role functioning, sexual activity, status of health insurance, global health-related quality of life, level of education and mean PSA before treatment.

Discussion: Comparative outcome studies for radical prostatectomy and brachytherapy ignore epidemiological differences. Our investigation demonstrate that younger age (odds ratio: 1.56) and higher scores of 'physical functioning' (odds ratio: 1.22) are strongly associated with a higher probability of receiving a surgical procedure when diagnosed with localized prostate cancer

Conclusions: Comparative outcome studies for different treatment modalities have to control their data for epidemiological differences, especially for age and physical functioning.

Keywords: Brachytherapy, epidemiology, incontinence, prostatectomy, prostate cancer, quality of life, urinary incontinence.

\section{INTRODUCTION}

Guidelines of the European Association of Urologists (EAU) [1] provide no distinct recommendation especially for patients with localized $\mathrm{T} 1 \mathrm{a}-\mathrm{T} 2 \mathrm{~b}$ prostate cancer as to whether radical prostatectomy (RP) or a form of brachytherapy (BT) is the optimum kind of treatment. The percentage of patients with a long time cure rate is quite high. Patients with poorly differentiated tumors have a tenyear survival rate between 45 and $65 \%$ and patients with well-differentiated tumors even have a mean survival rate of up to $90 \%$ [2-4]. Some authors state that in patients with well or moderately differentiated prostate cancer with a Gleason-Score of less than 5 to 7 , there is no survival difference between radical prostatectomy and brachytherapy $[5,6]$. Thus brachytherapy in the form of high-dose rate iridium brachytherapy (HDR) or low-dose rate 125-iodine (I-125) seeds application (LDR) have become common treatment methods for localized prostate cancer. Brachytherapy is often advertised as achieving superior health-related quality of life (HRQoL) [7]. The main side

*Address correspondence to this author at the Clinic of Urology, University Clinic Aachen, Pauwelsstr. 30, D-52057 Aachen, Germany; Tel: 0049-2418080068; Fax: 0049-241-8082441; E-mail: ruthkirsch@aol.com effects observed concern bladder and bowel function as well as impairment of sexual function [8-14]. Although incontinence is less frequent after brachytherapy than after surgery, patients having undergone BT frequently complain about lower urinary tract symptoms (LUTS) and urgency $[8$, 9]. Although data has been collected in recent years regarding complications and HRQoL after different treatment methods [10, 15], nearly all studies have a retrospective design and there is hardly any analysis on epidemiological differences between treatment groups. The purpose of this study is to find out if patients undergoing radical prostatectomy or various forms of brachytherapy differ in demographic or clinical data which might affect morbidity after treatment.

\section{METHODOLOGY}

Between 1999 and 2007, 856 patients with localized prostate cancer were treated in our institution; $598(69.9 \%)$ of them were treated surgically. Of the latter, $507(84.8 \%)$ patients underwent radical perineal prostatectomy (RPP) and $91(15.2 \%)$ radical retropubic prostatectomy (RRP). Two hundred and fifty-eight patients $(30.1 \%)$ received BT. Of these, $43.4 \%$ received a temporary Ir-192 High-Dose Rate radiotherapy boost (HDR) and $56.6 \%$ a permanent Low- 
Dose Rate - I-121 radiotherapy implant (LDR). All patients were seen by a urologist and a radio oncologist.

Patients who received external irradiation using threedimensional conformal radiotherapy (3D-CRT) or intensitymodulated radiotherapy were not seen by an urologist from our department and thus not included in our database. In the last few years minimal invasive techniques like laparoscopic and robot-assisted prostatectomy have become more popular but they were still low in number at our institution. Thus patients treated with these techniques were not included either.

Patients were accepted for LDR therapy according to the recommendation of the European Society of Therapeutic Radiology and Oncology (ESTRO), the European Association of Urology (EAU) and the European Organization for Research and Treatment of Cancer (EORTC) [16]. One urologist (HB) and one radiation oncologist (MP) performed all implants. Patients with T1c to T3pNo (Nx) M0 tumor were eligible for receiving HDR.

Radical perineal prostatectomy (RPP) with no lymphadenectomy was performed in patients with a PSA of $\leq 10 \mathrm{ng} / \mathrm{ml}$, a tumor of WHOG1-2, a Gleason-Score of $\leq 6$ and a stage T1c-T2bNxM0. In addition a laparoscopic pelvine lymphadenectomy was indicated in patients with a PSA of $\geq 10 \mathrm{ng} / \mathrm{ml}$ or a tumor WHO of G3 or a Gleason-Score of $\geq 7$ or a tumor staged T3. In our institution patients are permitted to receive radical retropubic prostatectomy (RRP) if a pelvine lymphadenectomy is indicated, the Gleason-Score is $\geq 7$ or the tumor is WHO G3 or higher. All radical prostatectomies were done by the author (GJ) and a senior resident of the department.

All patients received a self-administered 12-page questionnaire including a HRQoL questionnaire (EORTC QLQ C-30 with the prostate cancer module), questions regarding sexuality and the ICSmale questionnaire for urinary symptoms prior to therapy.

We evaluated above all the domains of the EORTC QLQ questionnaire according to the EORTC standards and the overall HRQoL. We also looked for LUTS, incontinence and urgency as a combination of several questions from the ICSmale questionnaire as stated in "Definitions."

Patients' characteristics were presented by means of median, minimum and maximum for numerical data and by absolute and relative frequencies for categorical variables. For the comparison of treatment groups, the Kruskal-Wallis test or Wilcoxon's rank-sum test and Fisher's exact test were used for numerical and categorical data respectively.

In a logistic regression analysis six variables (age, status of health insurance, level of education, PSA, global healthrelated quality of life, physical functioning) were further analyzed to detect parameters that independently affect the type of therapy patients received.

All tests were performed undirected (two-sided) and for any test a p-value below 0.05 was considered "significant" in an exploratory sense. Calculations were performed with SAS $^{\circledR}$, Version 8.2.

\section{RESULTS}

Data from all 856 patients treated for localized prostate cancer between 1999 and 2007 were collected in our database. Missing or incompletely filled-out questionnaires from $180(21 \%)$ patients could not be evaluated. Table $\mathbf{1}$ shows characteristics of the study cohort and Table 2 demonstrates that the subgroup of 676 patients, whose questionnaires could be evaluated, didn't differ in epidemiologic parameters. The mean age of the cohort group was 65.7 years (range 42 to $82 \mathrm{yrs}$ ). Patients envisaged for RPP were the youngest patients with a mean age of 64.4 years. Patients envisaged for HDR were the oldest patients with a mean age of 69.7 yrs. Most of the patients were covered by public health insurance (PUH) (67.1\%); 32.9\% had private health insurance (PRH). Patients covered by public health insurance underwent RRP (12.9\%) and HDR $(15.7 \%)$ more often as compared to patients with a private health insurance who were envisaged more frequently for RPP (68.5\%) and LDR (17.7\%). There was no significant difference between the therapy groups regarding family status or the size of the city they lived in. Fewer patients in the RRP group (11.1\%) had a higher-education entrance qualification (HEEQ) as compared to patients undergoing RPP (33.9\%; p: <0.05) or LDR $(29.5 \%$; p: <0.05). The mean Gleason-Score (6.22) and the mean PSA (12.03 ng/ml) differed significantly in all four therapy groups except when comparing the mean PSA and Gleason-Score in patients receiving RPP with patient envisaged for HDR (Table 3). We found the lowest mean Gleason-Score and mean PSA in patients envisaged for LDR which corresponds to the recommendations of the ESTRO/EAU/EORTC for brachytherapy. The data for prostate volume, tumor volume and $\mathrm{pT}$-stadium were collected postoperatively from patients undergoing RP. There was no significant difference in prostate volume (mean $60.93 \mathrm{ml}^{3}$ ) and $\mathrm{pT}$-stadium between the RPP and RRP group. Nerve sparing was done in $24.5 \%$ of the patients received RP.

The five different domains of EORTC QLQ C-30 were analyzed according to the recommendations of the EORTC. Questions on sexual activity were evaluated accordingly. On a scale from zero to 100 , higher values represent a better outcome. Patients before RPP had the best outcome in physical functioning (mean 94.34), role functioning (mean 92.54) and sexual activity (mean 60.43). In these three scores, we found the lowest values for people treated with HDR (mean 84.09; 88.07; 43.79). Direct comparison of all therapy groups provided significant differences between them (p: <0.05). However patients' values differed only little in cognitive functioning, social functioning and emotional functioning. Regarding HRQoL, patients envisaged for LDR scored best in baseline evaluation (69.83) contrary to patients envisaged for HDR with a mean score of 59.51 ( $\mathrm{p}<$ $0.01)$.

In five out of the six questions dealing with sexuality, patients prior to LDR indicated the greatest number of problems in partnership and the greatest decline in sexual interest, activity, joy and satisfaction. The patients' disease more often had a negative effect on the partnership of 
Table 1. Characteristics of Study Cohort

\begin{tabular}{|c|c|c|c|c|c|}
\hline \multirow{2}{*}{ Characteristics } & \multicolumn{4}{|c|}{ Therapy Groups } & \multirow{2}{*}{$\begin{array}{c}\text { Study Cohort } \\
\quad(\mathbf{n}=\mathbf{8 5 6})\end{array}$} \\
\hline & $\begin{array}{c}\text { OP/RPP } \\
(\mathrm{n}=507 ; 59.2 \%)\end{array}$ & $\begin{array}{c}\text { OP/RRP } \\
(n=91 ; 10.6 \%)\end{array}$ & $\begin{array}{c}\text { BT/HDR } \\
(n=112 ; 13.1 \%)\end{array}$ & $\begin{array}{c}\text { BT/LDR } \\
(n=146 ; 17.1 \%)\end{array}$ & \\
\hline \multicolumn{6}{|c|}{ Status of Health Insurance (\%) } \\
\hline Public & 36.7 & 8.6 & 10.5 & 11.2 & 67.1 \\
\hline Private & 22.6 & 2 & 2.6 & 5.8 & 32.9 \\
\hline Mean age (yr) & 64.4 & 65.8 & 69.7 & 66.9 & 65.7 \\
\hline Median age (yr) & 65 & 67 & 71 & 67 & 66 \\
\hline \multicolumn{6}{|l|}{ Family Status (\%) } \\
\hline alone & 12.7 & 18.5 & 13.6 & 11.2 & 13 \\
\hline not alone & 86.8 & 81.5 & 86.3 & 88.8 & 86.7 \\
\hline n.s. & 0.5 & - & - & - & 0.3 \\
\hline \multicolumn{6}{|c|}{ Place of Residence (\%) } \\
\hline big city & 25.6 & 23.5 & 35.6 & 23.5 & 26.4 \\
\hline City & 22.2 & 27.5 & 12.6 & 20 & 20.9 \\
\hline small town & 20.7 & 15.7 & 13.8 & 26.1 & 20.3 \\
\hline Village & 30.8 & 29.4 & 37.9 & 28.7 & 31.3 \\
\hline n.s. & 0.7 & 3.9 & - & 1.7 & 1.1 \\
\hline \multicolumn{6}{|c|}{ Number of Children (\%) } \\
\hline 0 & 5.7 & 2.3 & 2.7 & 5.8 & 5.1 \\
\hline 1 & 29.4 & 38.6 & 28 & 15.5 & 27.5 \\
\hline $2-3$ & 58.1 & 45.5 & 57.3 & 64.1 & 58.1 \\
\hline$>3$ & 6.8 & 13.6 & 12 & 14.6 & 9.3 \\
\hline \multicolumn{6}{|c|}{ Professional Status (\%) } \\
\hline Employed & 27.3 & 18.5 & 8.1 & 24.6 & 23.6 \\
\hline Retired & 70 & 79.6 & 92 & 72.8 & 74.2 \\
\hline Others & 2.7 & 1.9 & - & 2.6 & 2.3 \\
\hline \multicolumn{6}{|c|}{ Level of Education (\%) } \\
\hline HEEQ & 33.9 & 11.1 & 25.3 & 29.5 & 30.6 \\
\hline no HEEQ & 66.1 & 88.9 & 74.7 & 70.5 & 69.4 \\
\hline
\end{tabular}

patients envisaged for LDR (28.4\%) than of patients envisaged for surgical treatment (RPP: $22.9 \%$, RRP: $12.5 \%$ ) and HDR (22\%). However, these differences were not statistically significant. Nevertheless one should notice that most of the patients $(n=483 ; 77 \%)$ indicated that neither the disease itself nor the loss of sexuality had an influence on their partnership and the vast majority of patients $(n=513$; $83.1 \%$ ) stated that limited sexuality would not effect their partnership.

We further asked patients about symptoms of bladder function. We defined LUTS as the positive answer to at least one of the questions asked by the ICSmale questionnaire. $62.9 \%$ of the patients (425 patients) reported to suffer from LUTS to some extent. One in ten patients described LUTS as a bothersome problem (10.1\%). Of the study cohort, $51.3 \%$ indicated to have symptoms of urgency to some extent and $7.5 \%$ described these symptoms as bothersome even prior to therapy. However, we did not find any statistically significant difference in symptoms of the lower urinary tract with regard to the planned treatment mode (Table 4).

Since the health insurance status differed between treatment groups we also analyzed patients according to their status of health insurance (Table 5). About one third of the patients were covered by PRH $(32.9 \% ; n=281)$ and $67.1 \%$ were covered by a PUH $(n=573)$. Group analysis revealed that patients covered by $\mathrm{PRH}$, reached significantly better mean values in physical functioning (95.41; PUH: 91.01; $\mathrm{p}<0.01$ ), sexual activity (62.57; PUH: 55.2; $\mathrm{p}<0.01)$ and HRQoL (69.91; PUH. 64.14; $\mathrm{p}<0.01$ ). These data prompted us to include status of health insurance in our further analysis.

In a step-by-step logistic regression analysis, six variables (age, status of health insurance, level of education, 
Table 2. Characteristics of Study Cohort (Comparison)

\begin{tabular}{|c|c|c|c|}
\hline Characteristics & Study Cohort $(\mathrm{n}=856)$ & Pat with Filled out Questionnaires $(n=676)$ & p-Value \\
\hline \multicolumn{4}{|c|}{ Status of Health Insurance (\%) } \\
\hline Private & 32.9 & 34,3 & $\begin{array}{c}0,1070 \\
\text { n.s. }\end{array}$ \\
\hline Mean age (yr) & 65.7 & 65,2 & n.s. \\
\hline \multicolumn{4}{|l|}{ Family Status (\%) } \\
\hline alone & 13 & 13,6 & \multirow{3}{*}{$\begin{array}{c}0,8304 \\
\text { n.s. }\end{array}$} \\
\hline not alone & 86.7 & 86,0 & \\
\hline n.s. & 0.3 & 0,3 & \\
\hline Small town & 20.3 & 21,6 & \multirow[t]{3}{*}{ n.s. } \\
\hline Village & 31.3 & 30,3 & \\
\hline n.s. & 1.1 & 1,1 & \\
\hline \multicolumn{4}{|c|}{ Number of Children (\%) } \\
\hline 0 & 5.1 & 5,4 & \multirow{4}{*}{$\begin{array}{c}0,8412 \\
\text { n.s. }\end{array}$} \\
\hline 1 & 27.5 & 27,2 & \\
\hline $2-3$ & 58.1 & 58,6 & \\
\hline$>3$ & 9.3 & 8,8 & \\
\hline HEEQ & 30.6 & 32,7 & \multirow{2}{*}{$\begin{array}{c}0,2698 \\
\text { n.s. }\end{array}$} \\
\hline no HEEQ & 69.4 & 67,3 & \\
\hline
\end{tabular}

brachytherapy; yr. = years; .s. = not specified; HEEQ: higher-education entrance qualification.

PSA, HRQoL, physical functioning) were analyzed (operative treatment versus brachytherapy). Age $(\mathrm{p}<0.01)$ and physical functioning $(p<0.01)$ (Table 6) could be defined as independent variables that were significantly associated with treatment method. In the multi-regression analysis, status of insurance, level of education and pretherapeutic HRQoL was not linked to the treatment method. Further analysis confirmed that younger age (odds ratio: 1.56) and higher scores of physical functioning (odds ratio: 1.22) significantly increased the probability of receiving surgical procedure.

\section{DISCUSSION}

The optimum treatment for men with newly diagnosed early-stage prostate cancer remains controversial. Up to the early 1990s, radical prostatectomy had been the most common curative treatment for prostate cancer [1]. Since then different types of brachytherapy have become more popular. There is still no consensus regarding the question of which treatment is most effective, which one is associated with the least side effects and which one provides the best quality of life. In addition, in many countries, including Germany, not all forms of treatment are covered equally by different health insurances. By comparing epidemiological, clinical, oncological and social data, HRQoL and symptoms of the lower urinary tract we want to identify possible confounding parameters which might influence patients' and therapists' choice of treatment.

Similar to other studies $[15,17,18]$ we find significant differences in age. Patients envisaged for radical prostatectomy with a mean age of 64.4 years are significantly younger than patients envisaged for brachytherapy. Even studies with a statistically significant difference in patients' age before therapy $[10,14,19-21]$ ignore this difference in their outcome analysis 
Table 3. Comparison of Oncological Data Between Therapy Groups

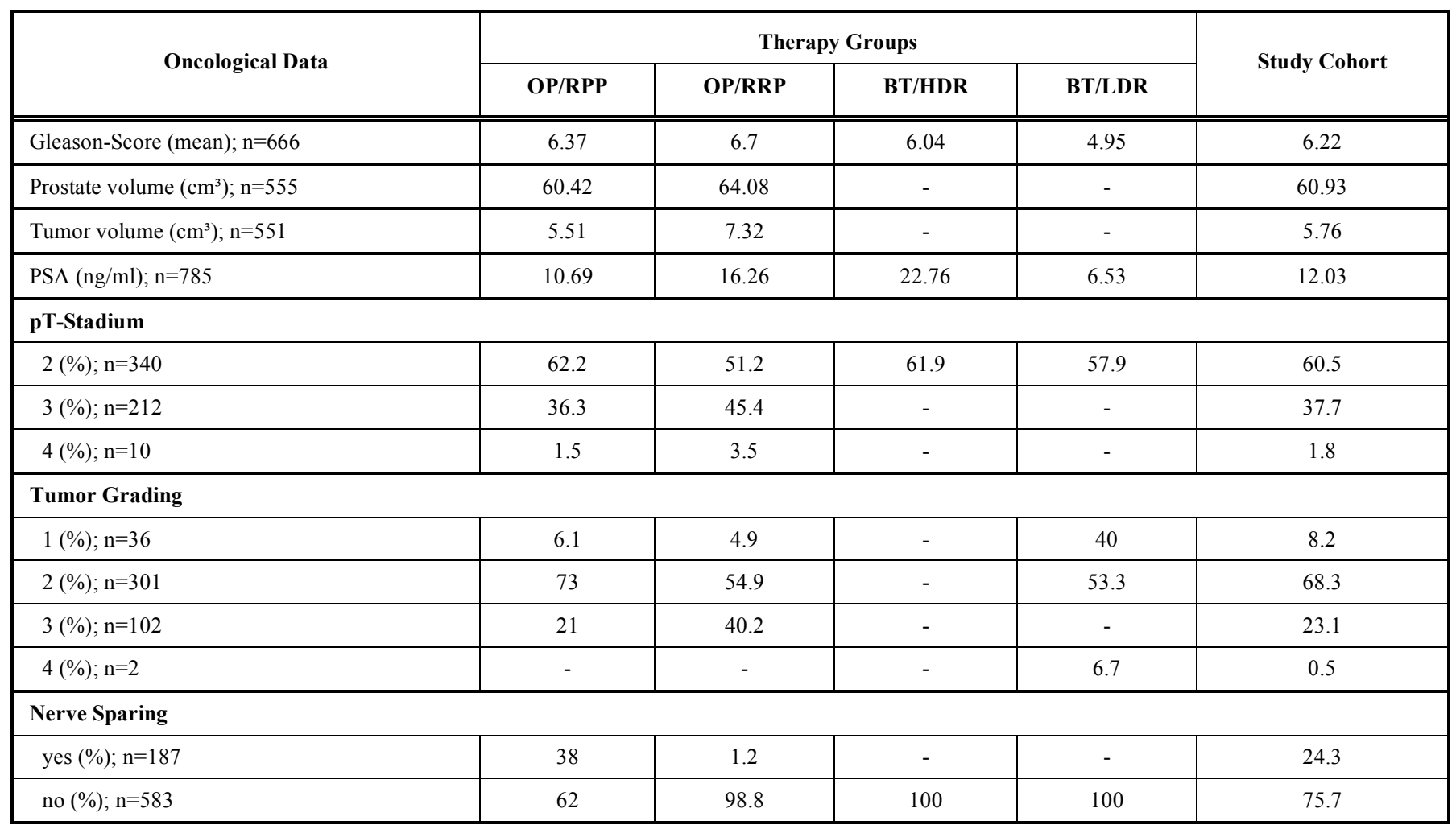

$\mathrm{OP}=$ operation; RPP = radical perineal prostatectomy; RRP = radical retropubic prostatectomy; BT = brachytherapy; HDR = high-doserate brachytherapy; LDR = low-doserate brachytherapy; PSA = prostate specific antigen.

although it is a well-known fact that the frequency of perioperative complications increases with age [22, 23]. However, it is not easy to determine whether the increased frequency of complications can be attributed to co-morbid conditions or whether advanced age itself is an independent risk factor [24]. Age notwithstanding, physical functioning is also significantly increases the likeliness of receiving surgical treatment.

It seems that doctors tend to recommend surgical therapy for younger as well as for fitter patients. This might be due to more oncological security. Sommers et al. state that choice of treatment often depends not on epidemiological and oncological but mainly on individual preferences regarding treatment- associated side effects [25]. However in our analysis LUTS did not differ between treatment groups. Furthermore, in two studies the specialist area of the physician advising the patient is the strongest predictor for choice of therapy. Patients seen by a radiation oncologist are more likely to choose BT whereas patients seen by an urologist were more likely to choose RP [26, 27]. In our survey, however, all patients evaluated are primarily seen by an urologist from our department. Other influences on patients' choice of therapy are feelings of fear and uncertainty about their diagnosis as well as misconceptions about different treatment options and their outcome. In addition, anecdotes from persons who have had experience with cancer influence patients' choice [28].

Table 4. General LUTS and Urgency in Relation to Therapy

\begin{tabular}{|c|c|c|c|c|c|}
\hline \multirow{2}{*}{ Voiding Function } & \multicolumn{4}{|c|}{ Therapy Groups } & \multirow{2}{*}{ Study Cohort } \\
\hline & OP/RPP & OP/RRP & BT/HDR & BT/LDR & \\
\hline \multicolumn{6}{|l|}{ LUTS } \\
\hline no LUTS (\%); n=251 & 37.3 & 37 & 29.6 & 42.4 & 37.1 \\
\hline Quite a problem $(\%), \mathrm{n}=357$ & 51.9 & 51.9 & 60.2 & 50.9 & 52.8 \\
\hline serious problem $(\%), \mathrm{n}=68$ & 10.8 & 11.1 & 10.2 & 6.8 & 10.1 \\
\hline no urgency $(\%), n=278$ & 40.6 & 44.4 & 36.4 & 44.9 & 41.1 \\
\hline Quite a problem $(\%), \mathrm{n}=347$ & 51.7 & 46.3 & 54.6 & 50 & 51.3 \\
\hline serious problem $(\%), \mathrm{n}=51$ & 7.7 & 9.3 & 9.1 & 5.1 & 7.5 \\
\hline
\end{tabular}

LUTS = lower urinary tract symptoms; OP = operation; BT = brachytherapy; RPP = radical perineal prostatectomy; RRP = radical retropubic prostatectomy; HDR = high-doserate brachytherapy; LDR = low-dose rate brachytherapy. 
Table 5. Comparison of Study Cohort in Relation to Health Insurance Coverage

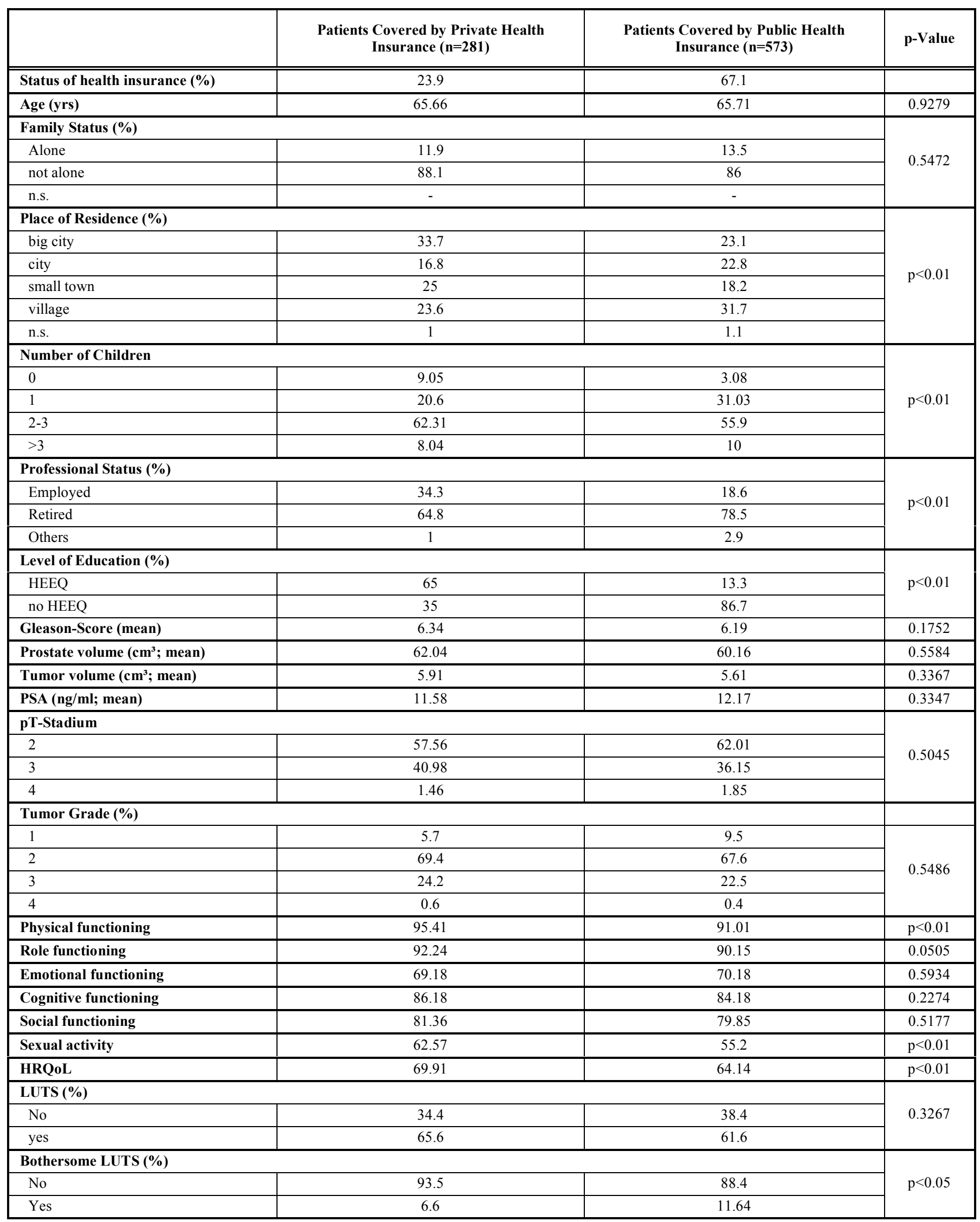

n.s.: not specified; LUTS: Lower Urinary Tract Symptoms; HEEQ: Higher education entrance qualification; HRQoL: Health-related quality of life. 
Table 6. Logistic Regression Analysis; Surgery Versus Brachytherapy - OP (RPP, RRP) Versus BT (LDR, HDR)

\begin{tabular}{|c|c|c|c|c|c|c|}
\hline Parameter & Odds Ratio & $95 \%-C I$ & p-value & Odds Ratio $^{1}$ & $95 \%-C I^{1}$ & p-Value ${ }^{1}$ \\
\hline Age & 0.64 & {$[0.54 / 0.77]$} & $<0.05^{*}$ & 0.636 & {$[0.55 / 0.74]$} & $<0.05^{*}$ \\
\hline Level of education & 1.011 & {$[0.88 / 1.17]$} & 0.885 & - & - & - \\
\hline PSA (median) & 1.45 & {$[0.97 / 2.16]$} & 0.0688 & - & - & - \\
\hline Physical functioning & 1.246 & {$[1.07 / 1.46]$} & $<0.05^{*}$ & 1.22 & {$[1.09 / 1.37]$} & $<0.05^{*}$ \\
\hline
\end{tabular}

*Statistically significant values; ${ }^{1}$ analysis of the two significant variables after omitting the four non-significant variables.

Our assumption that the choice of therapy might depend on the patients' level of education and information was confirmed by our data. The level of education differed significantly between treatment groups similar to the findings of Brandeis. Brandeis et al. [15] described that of his study cohort of 122 men, a significantly higher number of patients who received an operative treatment had a college degree or higher degree compared to patients who received a form of brachytherapy. Probably due to the size of our cohort group, we could not confirm the level of education as being an independent factor in a logistic regression analysis. Our findings regarding oncological data correlate with those of other authors and can to some extent be explained by different indications for one treatment option and common guidelines for treatment of prostate cancer [1].

Similar to the findings of Downs et al. [10], patients envisaged for RP achieved the best values in physical functioning and sexual activity, although sexual activity was not confirmed as an independent parameter in our multivariate analysis. Younger age and better physical functioning are the only independent parameters which are significantly associated with a greater probability of receiving surgical treatment rather than brachytherapy when diagnosed with localized prostate cancer. Thus both age and physical functioning have to be taken into account when analyzing treatment outcome.

\section{CONCLUSION}

Whereas age and physical functioning are significantly associated with a higher likeliness of being treated surgically (younger age (odds ratio: 1.56) and higher scores of physical functioning (odds ratio: 1.22)), other domains defined by the EORTC QLQ C30 such as cognitive functioning, social functioning and emotional functioning are not. The status of health insurance, albeit different between treatment groups, could not be defined as an independent variable associated with the treatment method. However one should keep in mind that patients covered by private health insurance scored significantly better in physical and sexual functioning, self-

perceived health status as well as motivation for a healthier way of life. Those factors might have an indirect influence on treatment outcome. Our data clearly demonstrates that we not only need prospective studies but that we also need to identify possible independent confounding variables at baseline if we want to compare the outcome of different treatment modalities. Only a multivariate analysis of confounding variables at baseline can identify independent factors which might influence treatment outcome.

\section{ACKNOWLEDGEMENT}

We were funded by a research grant from the German institute "Deutsches Institut für Rationale Medizin".

\section{DEFINITIONS}

LUTS is defined as a positive answer to at least one of the following questions neglecting severity of the symptom:

- Do you have to rush to the toilet to urinate?

- Does urine leak before you can get to the toilet?

- Does urine leak when you cough or sneeze?

- Do you ever leak for no obvious reason and without feeling that you want to go?

- Do you leak urine when you are asleep?

Incontinence is defined as a positive answer to at least one of the following questions, neglecting severity of the symptom.

- Does urine leak before you can get to the toilet?

- Does urine leak when you cough or sneeze?

- Do you ever leak for no obvious reason and without feeling that you want to go?

- Do you leak urine when you are asleep?

Urgency is defined as a positive answer to the following questions neglecting severity of the symptom:

- Do you have to rush to the toilet to urinate?

Stress incontinence is defined as a positive answer to the following neglecting severity of the symptom

- Does urine leak when you cough or sneeze?

A symptom is classified as bothersome if the patient states that the symptom is quite a problem or even a serious problem.

\section{REFERENCES}

[1] Aus G, Abbou CC, Bolla M, et al. EAU guidelines on Prostate cancer. Eur Urol 2005; 48: 546-51.

[2] Grimm PD, Blasko JC, Sylvester JE, Meier RM, Cavanagh W. 10year biochemical (prostate-specific antigen) control of prostate cancer with (125)I brachytherapy. Int J Radiat Oncol Biol Phys $2001 ; 51: 31-40$. 
[3] Lu-Yao G, Yao S. Population-based study of long-term survival in patients with clinically localised prostate cancer. Lancet 1997; 349: 906-10.

[4] Zincke H, Oesterling JE, Blute ML, Bergstralh EJ, Myers RP, Barrett DM. Long-term (15 years) results after radical prostatectomy for clinically localized (stage $\mathrm{T} 2 \mathrm{c}$ or lower) prostate cancer. J Urol 1994; 152: 1850

[5] Sharkey J, Cantor A, Solc Z, et al.103Pd brachytherapy versus radical prostatectomy in patients with clinically localized prostate cancer: a 12-year experience from a single group practice. Brachytherapy 2005; 4: 34-44.

[6] Kupelian PA, Potters L, Khuntia D, et al. Radical prostatectomy, external beam radiotherapy $<72 \mathrm{~Gy}$, external beam radiotherapy $>$ or $=72 \mathrm{~Gy}$, permanent seed implantation, or combined seeds/external beam radiotherapy for stage T1-T2 prostate cancer. Int J Radiat Oncol Biol Phys 2004; 58: 25-33.

[7] D'Amico AV, Vogelzang NJ. Prostate brachytherapy: increasing demand for the procedure despite the lack of standardized quality assurance and long term outcome data. Cancer 1999; 86: 1632-4.

[8] Mallick S, Azzouzi R, Cormier L, Peiffert D, Mangin PH. Urinary morbidity after 125I brachytherapy of the prostate. BJU Int 2003; 92: 555-8.

[9] Wagner TT, Nag S, Young D, Bahnson RR. Early voiding dysfunction associated with prostate brachytherapy. Urol Oncol 2000; 6: 20-3.

[10] Downs TM, Sadetsky N, Pasta DJ, et al. Health related quality of life patterns in patients treated with interstitial prostate brachytherapy for localized prostate cancer--data from CaPSURE. J Urol 2003; 170: 1822-7.

[11] Lee WR, Hall MC, McQuellon RP, Case LD, McCullough DL. A prospective quality-of-life study in men with clinically localized prostate carcinoma treated with radical prostatectomy, external beam radiotherapy, or interstitial brachytherapy. Int J Radiat Oncol Biol Phys 2001; 51: 614-23.

[12] Nag S, Beyer D, Friedland J, Grimm P, Nath R. American Brachytherapy Society (ABS) recommendations for transperineal permanent brachytherapy of prostate cancer. Int J Radiat Oncol Biol Phys 999; 44: 789-99.

[13] Krupski T, Petroni GR, Bissonette EA, Theodorescu D. Quality of life comparison of radical prostatectomy and interstitial brachytherapy in the treatment of clinically localized prostate cancer. Prostate Cancer Prostatic Dis 1999; 2: 32.

[14] Wei JT, Dunn RL, Sandler HM, et al. Comprehensive comparison of health-related quality of life after contemporary therapies for localized prostate cancer. J Clin Oncol 2002; 20: 557-66.
[15] Brandeis JM, Litwin MS, Burnison CM, Reiter RE. Quality of life outcomes after brachytherapy for early stage prostate cancer. J Urol 2000; 163: 851-7.

[16] Ash D, Flynn A, Battermann J, de Reijke T, Lavagnini P, Blank L. ESTRO/EAU/EORTC recommendations on permanent seed implantation for localized prostate cancer. Radiother Oncol 2000; 57: 315-21.

[17] Lim AJ, Brandon AH, Fiedler J, et al. Quality of life: radical prostatectomy versus radiation therapy for prostate cancer [see comments]. J Urol 1995; 154: 1420-5.

[18] Park R, Martin S, Goldberg JD, Lepor H. Anastomotic strictures following radical prostatectomy: insights into incidence, effectiveness of intervention, effect on continence, and factors predisposing to occurrence. Urology 2001; 57: 742-6.

[19] Litwin MS, Hays RD, Fink A, et al. Quality-of-life outcomes in men treated for localized prostate cancer [see comments]. JAMA 1995; 273: 129-35.

[20] McCammon KA, Kolm P, Main B, Schellhammer PF. Comparative quality-of-life analysis after radical prostatectomy or external beam radiation for localized prostate cancer. Urology 1999; 54: 509-16.

[21] Shrader-Bogen CL, Kjellberg JL, McPherson CP, Murray CL. Quality of life and treatment outcomes: prostate carcinoma patients' perspectives after prostatectomy or radiation therapy. Cancer 1997; 79: 1977-86.

[22] Tiret L, Desmonts JM, Hatton F, Vourc'h G. Complications associated with anaesthesia--a prospective survey in France. Can Anaesth Soc J 1986; 33: 336-44.

[23] Arvidsson S, Ouchterlony J, Nilsson S, Sjostedt L, Svardsudd K. The Gothenburg study of perioperative risk. I. Preoperative findings, postoperative complications. Acta Anaesthesiol Scand 1994; 38: 679-90.

[24] Mangano DT. Perioperative cardiac morbidity. Anesthesiology 1990; 72: 153-84.

[25] Sommers BD, Beard CJ, D'Amico AV, et al. Decision analysis using individual patient preferences to determine optimal treatment for localized prostate cancer. Cancer 2007; 110: 2210-17.

[26] Sommers BD, Beard CJ, D'Amico AV, Kaplan I, Richie JP, Zeckhauser RJ. Predictors of patient preferences and treatment choices for localized prostate cancer. Cancer 2008; 113(8): 205867.

[27] Fowler FJ, Jr., McNaughton CM, Albertsen PC, Zietman A, Elliott DB, Barry MJ. Comparison of recommendations by urologists and radiation oncologists for treatment of clinically localized prostate cancer. JAMA 2000; 283: 3217-22.

[28] Denberg TD, Melhado TV, Steiner JF. Patient treatment preferences in localized prostate carcinoma: The influence of emotion, misconception, and anecdote. Cancer 2006; 107: 620-30.

Received: July 18, 2010

Revised: November 11, 2010

Accepted: November 13, 2010

(c) Kirschner-Hermanns et al.; Licensee Bentham Open.

This is an open access article licensed under the terms of the Creative Commons Attribution Non-Commercial License (http://creativecommons.org/licenses/by$\mathrm{nc} / 3.0 /$ ) which permits unrestricted, non-commercial use, distribution and reproduction in any medium, provided the work is properly cited. 